\title{
Is literary language a development of ordinary language?
}

Nigel Fabb

Version of 29 July 2009, corr. 25-11-09

To be published in Lingua

\section{$\underline{\text { Abstract }}$}

Contemporary literary linguistics is guided by the 'Development Hypothesis' which says that literary language is formed and regulated by developing only the elements, rules and constraints of ordinary language. Six ways of differentiating literary language from ordinary language are tested against the Development Hypothesis, as are various kinds of superadded constraint including metre, rhyme and alliteration and parallelism. Literary language differs formally, but is unlikely to differ semantically from ordinary language. The article concludes by asking why the Development Hypothesis might hold.

Keywords

metre, alliteration, rhyme, parallelism, literary linguistics, literary language.

$\underline{\text { Text }}$

1. Literary language and ordinary language

Poems, novels, oral narratives, songs, and other literary texts are composed in language which may be different from ordinary language. The differences (described in section 2) include various rearrangements or alterations of words, sounds and syntax, often as the result of imposing external constraints such as metre or rhyme. In this article I refer to language which manifests these differences as 'literary language'. Literary language is found in paradigmatically literary genres such as poetry, but also borderline literary genres such as oratory or other kinds of 'heightened' discourse, such as advertising or certain genres of conversation.

Literary language can differ from ordinary language in its lexicon, phonology and syntax, and may present distinctive interpretive difficulties.

"Is Balder dead? and do you come for tears?

Thok with dry eyes will weep o'er Balder's pyre.

Weep him all other things, if weep they will - 
I weep him not! let Hera keep her prey."

Matthew Arnold "Balder Dead"

The lines above contain unusual words (names, such as Thok) and phonology ( $o$ 'er pronounced as a monosyllable). The sequence weep him all other things has a verbobject-subject order which differs from ordinary English. And the contradiction in with dry eyes will weep is a characteristically 'literary' difficult meaning. Literary language can also differ by being subject to superadded constraints such as metre or rhyme: the words in this text must be arranged into ten-syllable sequences (iambic pentameter lines).

Most literary linguistics, for example in the generative framework, has assumed that there is a special relation between literary language and ordinary language. I formulate this as what I call the 'Development Hypothesis', and devote this article to exploring whether it is true, and what its implications are.

The Development Hypothesis: Literary language is governed only by rules and constraints which are available to ordinary language, and which refer only to representations which are present (at some stage in a derivation) in ordinary language.

The Development Hypothesis says that literary language is a development of ordinary language. The alternative is that literary language contains elements not found in ordinary language or is governed by rules or constraints which are not found in ordinary language. The Development Hypothesis is a formulation of a widely expressed view about the dependence of literary language on ordinary language. Sapir concludes his 1921 book Language with this: "Study carefully the phonetic system of a language, above all its dynamic features [prosody], and you can tell what kind of a verse it has developed - or, if history has played pranks with its psychology, what kind of verse it should have developed and some day will." (Sapir 1967: 230). And Kiparsky, in his seminal 1973 article on literary language as a development of ordinary language says that "[ $\mathrm{t}]$ he linguistic sames which are potentially relevant in poetry are just those which are potentially relevant in grammar." (Kiparsky 1981: 13).

The Development Hypothesis has a strong form and a weak form. In the strong form (as stated by Sapir), a literary language is a development of its source language. Thus Kiparsky (1981: 9) says that that "[a]1literation... seems to be found as an obligatory formal element only in languages where the stress regularly falls on the same syllable in the word, which then must be the alliterating syllable". The weak version of the Development Hypothesis allows a literary language to be a development of the universal possibilities underlying all languages. Kiparsky (1981: 19) uses the weak version when he says that that alliteration is managed by the same rules or conditions as organize the morphological process of reduplication. This is a weak version of the hypothesis, because alliteration is found in literatures (such as English) whose morphologies do not include reduplication.

The Development Hypothesis depends on a distinction between 'natural literary language' and 'artificial literary language', where only the former is expected to conform to the hypothesis, and the latter does not. The possibility of artificial literary language can be seen in the fact that an author can write or say anything they want: any constraint can be applied to a text, and any variation in the language is possible. Avant-garde writing amply demonstrates this: see for example the texts anthologized in Rothenberg and Joris $(1995,1998)$, or the practices of the Oulipo 
movement (Mathews and Brotchie 2005). Sapir acknowledges this problem, saying that some writers do indeed transgress the laws of language, and as a result produce "a translation from an unknown original": he cites Robert Browning and Walt Whitman as examples. The Development Hypothesis thus forces a line to be drawn between literary texts which conform to it, and literary texts which do not; for it to have any force as a hypothesis, there should be some further way of testing this distinction. We might for example set an 'epidemiological' test which asks whether the formal practice is used repeatedly (i.e., forms part of a tradition), or whether the formal practice is used just in one text (or perhaps just by one author). Literary forms which develop linguistic forms should be repeated; those which have arbitrary form should not be repeated. This test, incidentally, could be used to show that Sapir was wrong to exclude Browning and Whitman, because both of these writers have been widely imitated; hence we would expect them to conform to the Development Hypothesis, and in fact Kiparsky (1981:15) explicitly discusses Whitman's use of parallelism as a development of ordinary language syntax.

The possibility that aesthetic products can be partitioned into two kinds, one fitting cognition, and the other arbitrary relative to cognition ('cognitively opaque'), has been more systematically explored for music than for literature. For example, Lerdahl (1988) argues that the rules of composition of Pierre Boulez's masterpiece Le Marteau sans Maître do not depend on the basic principles of musical cognition and so are not recoverable by the hearer: instead, the hearer can develop an internal representation of the music, but it will be a different representation from that formulated by its composer. Lerdahl compares this with the music of, for example, Beethoven, where the rules of composition and audition can be the same, as both are developments of ordinary musical cognition. We might similarly say that some literary texts operate according to ordinary literary-linguistic cognition, and other literary texts operate according to other nonlinguistic cognitive principles. The Development Hypothesis applies only to the former set of texts: we exclude the avant-garde from consideration.

2. Six ways in which literary language differs from ordinary language.

In this section I distinguish six types of difference which define the distinction between literary language and ordinary language; these six types fall into two general kinds, as I now illustrate. In the first line of the stanza below, we can see a way in which literary language is formally identical to ordinary language: these are ordinary words in an ordinary order. What makes the language 'literary' is not the text itself, but the fact that it takes its particular form only because it is subject to a superadded condition requiring the words to be grouped into a line with four stressed syllables, here sun, rose, -on and right.

The Sun now rose upon the right:

Out of the sea came he,

Still hid in mist, and on the left

Went down into the sea.

S.T. Coleridge, "The Rime of the Ancient Mariner" 
Sometimes literary language is altered so that it no longer has the form of ordinary language, and this is true of the second line of this text, with its complement-verbsubject order. I now illustrate some of the ways in which literary language can differ from ordinary language.

\subsection{Redeployment}

Literary language can be ordinary language redeployed, so that the text conforms to some superadded constraint.

I grant indeed that fields and flocks have charms

For him that grazes, or for him that farms;

George Crabbe, "Village Life - as it is"

The superadded constraints which impose division into rhyming iambic pentameter lines are obeyed while keeping the language ordinary: this is a text which could be generated by ordinary phonological and syntactic rules, with ordinary sounds and words and syntax. The Development Hypothesis has nothing to say about redeployment because by definition the literary language under redeployment is just the same as ordinary language.

\subsection{De-structuring}

Two texts can be the same length, while differing in the extent to which they are syntactically structured. A text made from a large number of short sentences has less overall syntactic structure than a large text made from a single complex sentence. In ordinary language, words or phrases, or pieces of text, can be put next to one another (concatenated) without there being any syntactic relation between them, for example when lists are formed. Furthermore, some syntactic relations such as co-ordination may be relatively unstructured compared to syntactic relations in general. The use of concatenation, co-ordination and similar devices (parentheticals, appositions, etc) can be thought of as ways of de-structuring a text. De-structuring is quite common in ordinary language, and is very common in literature and particularly in verse, where listing, apposition, and co-ordination are crosslinguistically common, perhaps as a way of enabling the language to conform to superadded constraints.

The Development Hypothesis has an ambiguous status relative to destructuring. On the one hand, de-structuring is characteristic also of ordinary texts, and the devices are all drawn form ordinary language (in keeping with the Hypothesis). But on the other hand, de-structuring makes the Hypothesis less interesting because it makes both ordinary language and literary language 'less linguistic', and hence any link between them less remarkable.

In Fabb (2009a) I make a radical proposal about the structure of verse, which emphasizes de-structuring, and is in explicit opposition to the Development Hypothesis. I briefly summarize this proposal now. How is verse composed? The answer to this question must explain how it is that the words are grouped into sequences (lines) of a certain length, with a certain rhythm, and perhaps with rhymes or other features in specific places. One possibility is that verse is generated first as 
prose, by the usual syntactic processes, and then re-edited into lines, with some reordering of the parts to fit the external constraints. Undoubtedly, this sometimes happens. But I propose an alternative in which lines are composed by linear concatenation of elements: they are composed without syntax, for example just stringing lexical items one after another. Phrases or parts of phrases can also be strung together (i.e., parts of the line might be fully formed phrases with internal syntax), but the overall principle of combination is concatenation, not merge or some other syntactic rule. Lines are thus composed directly, as units, and not re-edited from prose. If this is true, it means that lines are radically de-structured, and their organization cannot be seen as a development of ordinary language. There is, however, a further component to this account, which must explain two things: (i) if lines are composed by concatenation, why do they often look as though they were composed by syntactic rules, and (ii) if lines have no syntax, and therefore no logical forms, how do they deliver interpretations? I answer these two questions by suggesting that lines are subject to a meta-constraint which is that the line must resemble ordinary (syntactically-generated) text, and 'steals' an interpretation from the text which it resembles. This is achieved by separately generating prose text (but not producing it as spoken output), alongside the independently concatentated line (which is produced as spoken output). The line and the separately generated prose must be similar (subject to variation as permitted within the genre). I argue that this approach to verse, which is primarily concerned with how verse is composed (i.e., by avoiding syntax), explains some characteristics of verse. For example, it explains why verse can apparently have 'crazy syntax' (discussed further in 2.5), because verse actually has no syntax. It explains how factors other than meaning can drive composition in verse, and it explains why verse has more metaphors and other types of non-literal meaning: whereas standard models of speech suggest that word-choice is driven by meaning, in this model, word-choice can be driven by any characteristic of the word, and meaning may emerge by accident.

\subsection{Looseness of fit}

Many superadded constraints allow some looseness of fit between the constraint and the language of the text. A commonly-encountered type of looseness of fit involves sound patterning rules where non-identical sounds are counted as the same, because they share some, but not all, phonetic features. In Irish syllabic poetry (Knott 1994: $5)$, rhyme is possible between syllables which end in different voiced plosives (b, $d$, $\mathrm{g}$ ) or between syllables which end in different voiceless plosives ( $\mathrm{p}, \mathrm{t}, \mathrm{k})$. This is looseness of fit because non-identical sounds are treated as the same. It fits with the Development Hypothesis, because the grouping of sounds is based on linguistic form: voicing and manner features are taken into account but not the place feature. If we found a rhyme scheme where for example the rhyming sets involved $[\mathrm{p}, \mathrm{t}]$ and $[\mathrm{k}, \mathrm{d}]$ and $[b, g]$, then we would have found an example of looseness of fit which violates the Development Hypothesis (such a scheme has not been reported).

Another common type of looseness of fit involves the 'skipping' of syllables which may be pronounced but are not counted for metrical purposes. Thus, Fabb and Halle (2008) argue that metres always determine the number of syllables in the line, but some pronounced syllables are invisible to the metrical rules. 
Yet dearly I love you, and would be loved fain.

John Donne

In this iambic pentameter line (discussed by Fabb and Halle 2008: 60-2), there are twelve syllables (if we pronounce lovè as a disyllable), but iambic pentameter stipulates that there should be ten. This is achieved by not counting the two syllables $l y$ and you, even though these syllables are pronounced. This is a looseness of fit which does not affect the pronunciation of the line, but only how the line is scanned. The Development Hypothesis is strengthened if there is a phonological basis for not counting specific syllables (as Hanson and Kiparsky 1996 argue), and weakened if syllables can be excluded arbitrarily (as Fabb and Halle argue).

\subsection{Disregarding}

Kiparsky (1981: 21) says that "[i]t sometimes happens that phonological schemes such as metre and rhyme must be attached to linguistic forms before certain phonological rules have applied to them". Following Kiparsky, I use the term 'disregarding' to describe access to an underlying form (i.e., disregarding later phonological rules): note that again the text is not actually altered - phonologically it is the same as ordinary language, and it is its obedience to constraints which makes it literary language. For example, Kiparsky (1970: 172) shows that in Finnish the operation of a sequence of ordered rules "is disregarded in the metrics": for example, the word kottiin is positioned in a metrical line such that its surface form is unmetrical but its underlying form / kotihin/ would be metrical. By disregarding the rules of contraction and gemination, it is possible for the metrical rules to see the word in this position as kotihin thus meeting the requirements of the metre. Another example of disregarding is rhyme in Turkish suffixes, where specific vowels can rhyme with specific other vowels. Malone (1982) shows that the possible rhymes cannot be parsimoniously explained by the sharing of features between vowels (i.e., not looseness of fit), but can be simply explained by the fact that the relevant suffixes have an identical underlying form before harmony processes spread features from the stem (i.e., disregarding). The Development Hypothesis is strongly evidenced to the extent that it can be shown that the literary rules have access to underlying linguistic form.

Disregarding, by its nature, always conforms to the Development Hypothesis because it is based on accessing a covert form of the word, which has a strictly linguistic relation to the overt form. Disregarding in fact is very strong evidence for the Development Hypothesis, and may reflect the phenomenon of 'phonological awareness' noted by Sapir, where speakers appear to have access to underlying forms (see Fabb and Halle 2008: 133, for further discussion). The proponent of disregarding must however demonstrate that the covert form is not revealed in some way on the surface of the text in the spelling of the word (which can reveal underlying phonology), or is not the result of remembering an archaic or dialect variant of a word. 


\subsection{Alteration}

The first four ways by which literary language differs from ordinary language all involved the language being formally the same as ordinary language. Now we look at 'alteration' and (in section 2.6) 'neologism', two ways in which literary language is different in form from ordinary language.

Literary language is 'altered' if it looks in part like ordinary language but has been changed in a way not possible in ordinary language. For example, syllables can be added or suppressed. A syllable is added in the line by Donne quoted in 2.3, where loved is pronounced as a disyllable. The same line can be pronounced with syllables suppressed. I suggested earlier that the line can be given a normal pronunciation of twelve syllables, but scanned with ten syllables (looseness of fit), but it is of course also possible to alter the pronunciation of Donne's line so that it has just ten syllables (e.g., dearly I pronounced as two syllables instead of three). The language can also be altered by changing the prosodic structure. For example, words in the Australian language Dyirbal normally have initial stress, but in songs in the marrga metre, stress is reassigned to the first, fourth, sixth and eighth syllables in the 8-syllable line, irrespective of whether these syllables would normally be stressed (Dixon and Koch 1996: 181).

Syntax can also be altered, in two distinct ways. One alteration is to put words or phrases in an order which cannot be derived in the ordinary language. A different alteration is to disconnect syntax from information structure. Both can be seen in the following text.

Not all to that bright station dared to climb;

And happier they their happiness who knew,

Whose tapers yet burn through that night of time

In which suns perished.

P. B. Shelley, "Adonais”

Austin (1984: 38) comments that "[w]hatever the movement rule responsible here for shifting their happiness from its underlying position as the post-verbal direct object of knew to its location in surface structure immediately before who, that rule has clearly applied in violation of the Tensed S Condition, of the Doubly-Filled Complementizer Constraint, or of both at once." Though this is formulated in terms of the Extended Standard Theory (generative syntax of the late 1970s), the basic point still holds true: the second line has a form which cannot be derived by ordinary syntactic rules.

Austin argues that the lines are generated by the rules of ordinary syntax but with a difference: the two syntactic constraints are ignored. Thus the grammar is selectively altered, in forming this poem. In effect, the Development Hypothesis is still obeyed here: the alteration is strictly guided by the organization of the syntax, such that by 'turning off' part of it, the altered form is produced.

Another kind of crazy syntax is seen in Icelandic poetry, discussed by O'Neil (2001), who shows that constituents, including individual words, can be radically reordered. Nevertheless, this is still subject to a constraint that "[r]aising proper parts of a constituent is allowed, but only to the edges of the clause, with raising to a rightadjoined position only if there is raising to [Spec, DP]." Again, the Development 
Hypothesis plays a role here: crazy syntax still operates with some regard to the operations of ordinary syntax.

Shelley's text involves alteration in the sense that the structure cannot be generated by ordinary syntactic rules. But we might note that there is also a mismatch between structure and interpretation, in that words and phrases are moved around within the line without any clear interpretive consequence: they are not obviously topicalized, or focused, for example. It seems that in poetry we abandon the expectation that the syntax strongly codes for information structure. As Constable and Aoyama (1999: 517) put it, in verse, the presence of external (not interpretively driven) constraints on form such as metre mean that for poetry it is more difficult to decide which implications are implicatures; that is, which of the possible interpretations implied by the text are deliberately implied by the author, as opposed to having arisen accidentally as a result of external constraint-driven movement. It is possible that the separation of syntax and semantics which we see here is a more fundamental violation of the Development Hypothesis than the relatively localized violations of syntactic rules discussed above. Within Optimality Theory, there have been proposals for solving this problem; if the syntax is combined within a unified system (i.e., an ordering of constraints) with the prosodic rules, then prosody can be made to have a direct influence on syntax by large-scale reordering of systems of constraints. Thus Golston and Riad (2000: 103) say that in poetry, prosody outranks syntax. Fitzgerald (2007) argues that some syntactic rules outrank some prosodic rules and are outranked by others. Whether major structural re-ranking of this kind (not seen in ordinary language) conforms to the Development Hypothesis depends on larger theoretical considerations about the holistic organization of constraints, and the possibilities of re-ranking.

\subsection{Insertion}

The most extreme way of differentiating literary language from ordinary language is to insert words which have been borrowed from another dialect or language, or from an older form of the language, or invented. Archaism, the borrowing of older forms, is common, partly for symbolic reasons because literary texts may express conservative or 'golden age' values through the symbolic deployment of recognizably older language. Names can be thought of as insertions into a text, particularly when they have alien phonological forms. Some types of literature make particular use of foreign names: science fiction, travel literature, historical literature, and literature which borrows myths and heroes from other cultures. An interesting characteristic of foreign names in English poetry is that they have flexible stress patterns, turning these inserted words into metrical 'wild cards'. Halle and Keyser (1971: 104) show that the name 'Criseyde' in Chaucer's Troilus and Criseyde can be stressed on any of its syllables, and Fabb (2002: 40) shows the same for the name 'Hero' in Marlowe's Hero and Leander.

Neologism, the invention of new words, is the most radical type of insertion. It is found in Dyirbal songs, for example, where a word may be invented for a specific song, to fit the strict metrical requirements (Dixon and Koch 1996: 29). Texts may be extensively neologistic; examples include Joyce's Finnegans Wake or Drummond's "Polemo-Middinia inter Vitarvam et Nebernam" in a macaronic mixture of Latin and English (e.g., "scopulis lobster mony-footus in udis / Creepat"; Crawford and Imlah 
2000: 192). In some cases, these texts are governed by entirely artificial principles, and cannot be seen as developments of natural language. MacMahon (1995) shows this for Finnegans Wake, rejecting the psychoanalytic accounts which claim that the words in the book are like real 'slips of the tongue', and showing instead that no linguistic principles underlie the formation of the words.

On the one hand, insertion and particularly neologism work against the Development Hypothesis, and radical insertion/neologism (as in Finnegans Wake) takes a text over the boundary into a realm where we cannot expect the Development Hypothesis to work. But it is also true that ordinary language involves various kinds of insertion, including the use of foreign words and neologisms, with distinctive characteristics such as their phonology, even within the ordinary language. For example in the Central Sudanic language Ma'di, foreign words have a distinctive tonal pattern and their own plural morphology (Blackings and Fabb 2003: 68). In this sense, the insertions of literary language develop possibilities found in every ordinary language, and the Development Hypothesis is sustained.

\section{Literary language is subject to superadded modes of organization}

In section 2, I distinguished various ways of differentiating literary language from ordinary language. Many of these differences depend on superadded constraints which are imposed on literary texts, such as constraints of metre or rhyme. In this section I look at some of the superadded constraints: the Development Hypothesis predicts that they are developments of constraints or rules which are found in ordinary language. As we will see, this is partially true, and partially untrue.

\subsection{Lineation}

A text is lineated, or in lines, if it is divided into non-linguistic sections of a certain length; lines have edges but do not obviously have any internal structure. Lineation is an abstract characteristic of a text which can be made manifest in various ways: it can be represented in printed layout (but texts can be underlyingly lineated yet printed as prose), or in performance (by pausing at line-ends), or lineation can be manifested via the constraints which depend on lineation such as metre or alliteration or rhyme or parallelism. Since by definition, lines are non-linguistic sections, they are a problem for the Development Hypothesis. Though they are combinations of words (like syntactic structures) they have a structure which has no parallel in syntax because lines are not internally asymmetric, headed structures: thus it seems that the line is not a development of a linguistic form.

Lineation holds of texts which have linguistic structure (even if this is destructured as described above, 2.2), and one role for the Development Hypothesis is to show that there are generalizations about the relation between linguistic structure and lineation. In some cases, the line coincides very closely with linguistic constituent boundaries (in Persian poetry, the sequence of words which comprise the line also comprises a sentence). In other cases, the line can end even in the middle of a word (in Greek lyric poetry; other examples are discussed in Fabb and Halle 2008). In French classical tragedy, the possibility of enjambment is tightly controlled (Wexler 1966), with specific kinds of syntactic structure allowed to be divided in specific 
ways across the line boundary; this shows a relation between linguistic structure and line structure which is loosely in keeping with the Development Hypothesis.

\subsection{Metre}

A line is metrical when superadded rules or constraints regulate the number and prosodic characteristics of the syllables comprising the line; for example, English iambic pentameter is (broadly speaking) a metre which fixes the line at ten syllables, with even-numbered syllables tending to be stressed. While all metres control the number of syllables, the control can be rigid, or loose, and can be indirect (e.g., by controlling morae, or by allowing stressed syllables to have a special status in counting). The fixing of syllables in certain positions in the line (i.e., the control of rhythm) may depend on stress, or quantity, or lexical tone, or occasionally some combination of these. Some metres in addition require a word boundary to fall in a specific numbered position within the line: French alexandrin metre fixes the line at twelve syllables and requires the sixth metrical syllable to be word-final.

There are many different linguistic theories of metre (e.g., Hanson and Kiparsky 1996, Golston and Riad 2000, Hayes 2008, Fabb and Halle 2008). Most linguistic theories of metre share the view that a line is made to be metrical by making it conform to a representation in the form of a grid or tree which has been generated by a specific set of rules and/or constraints. In keeping with the Development Hypothesis, the representation and rules/constraints are expected to be similar to those used in ordinary language in the assignment of stress within words. For example, Fabb and Halle (2008) use for metre the rules formulated by Idsardi (1992) for the assignment of stress in words. The rules in both cases generate a bracketed grid from a string of syllables, comprising the word for Idsardi, or comprising the line for Fabb and Halle. For word stress, an additional rule assigns stress to syllables based on their projection into the grid. For metre, a condition checks that syllables with specific prosodic characteristics project to specific positions in the grid.

Metrical rules fix the number of syllables in the line: for example, the iambic pentameter line has ten syllables (with some controlled variation). Counting is something no linguistic rule ever does: as with lineation, we find a phenomenon in literary language which has no direct analogue in ordinary language. Fabb and Halle explain the counting of syllables by adding meta-constraints to their grid-building rules; hence this can be seen as a development of the rules of ordinary language, to produce a result which differs significantly from what ordinary language rules do. In a metrical grid, every gridline must have iterative rules (hence groups of elements no larger than three), there are a fixed number of gridlines in each metre, and the final gridline must contain one asterisk; of these meta-constraints only the last holds also in the assignment of word-stress. (Fabb and Halle also argue that musical metres are controlled by similar rules, subject to the first but not the latter two meta-constraints.)

Though there are differences between metrical rules and word-stress rules, these differences can be seen as ways of making different literary use of essentially the same materials as in ordinary language. Consider, for example, what does not happen. Amplitude, pitch, and duration are all characteristics of the speech stream which in principle could be used as a basis for organizing a text into rhythmic patterns; but these are systematically part of a poetic rhythm only when they are mediated through the phonological system (e.g., amplitude is relevant for patterns in literature only via stress). Similarly, there appear to be no complex metre-like 
organizations on the basis of non-linguistic but identifiable characteristics of speech such as timbre, or speech style, or pace. Thus the Development Hypothesis is broadly confirmed by poetic metre.

\subsection{Rhyme and alliteration}

Prototypical alliteration is a relation between syllables which share the same onset. Prototypical rhyme is a relation between syllables which share the same nucleus and coda. Rhyme and alliteration are relations between syllables with identical components. This can be identity after looseness of fit (section 2.3), e.g., identity of some shared feature. It can also be identity after disregarding (section 2.4), e.g., identity of underlying rather than surface form). Sometimes the morphological status of the word can also be relevant: in a particular tradition, rhyme may be permitted between homophonous suffixes only if they are different morphemes (Worth 1977: 518, citing Jakobson on Slavic rhyme). This all conforms to the Development Hypothesis, as does the fact that the various kinds of alliteration and rhyme all refer to component parts of a syllable and so make phonological sense: as Kiparsky points out, there are no rhyme rules which pick out the penultimate sound in a word (a nonlinguistic identity).

In addition to prototypical alliteration and prototypical rhyme, there are various other relations which might be classified as alliteration, or as rhyme, or possibly as another distinct category: these include repetition of onset + nucleus (Finnish and Mongolian, sometimes called alliteration and sometimes reverse rhyme), repetition of just the nucleus (sometimes called assonance and sometimes considered to be a kind of rhyme), repetition of just the coda (sometimes called consonance and sometimes considered to be a kind of rhyme), and repetition of onset and coda but not the nucleus (sometimes called slant rhyme). Any typology of sound patterning depends on whether a principled distinction can be made between alliteration and rhyme, and if so, how this principle sorts the other kinds of sound patterning. For example, Fabb (1999) argues for a distinction between alliteration and rhyme: alliteration holds between adjacent sections of text, but rhyme need not (and so can form ABAB patterns, unlike alliteration). On this basis, we would classify the Finnish and Mongolian onset + nucleus repetitions as alliteration because they are strictly local (within the line, or between adjacent lines), and not classified as (reverse) rhyme. Note that this difference between alliteration and rhyme has no clear basis in language, and so is not in keeping with the Development Hypothesis.

Kiparsky (1981: 19) suggests that the specific kinds of repetition involved in rhyme and alliteration are found also in ordinary language, in the morphological process of reduplication (see also Holtman 1996, Yip 1999). Stanford (2007) shows for example that in Sui, adjectives can be intensified by reduplication where either the onset or the nucleus + coda are repeated. The former resembles alliteration; an example is $z a$ 'light' and $z a z u$ 'very light'. The latter resembles rhyme; an example is lap 'garrulous' and lap tap 'very garrulous'. It is possible to have rhyme and alliteration in a language without reduplication, so the Development Hypothesis in this case must see a specific literary language as developing a universal possibility, rather than something from the source language. Another source of rhyme and alliteration in ordinary language is in idiomatic expressions or nonce-words which have alliteration or rhyme, or some variant on these: Kiparsky points out that para-rhyme in poetry is like the pattern in the ordinary combination tick tack tock. This all fits with the 
Development Hypothesis, as it means that alliteration and rhyme in poetry are extensions of practices found in everyday language.

Rhyme and alliteration have also been subject to psycholinguistic exploration, with implications for literature. It seems that rhyme, alliteration and other constraints on the text have a number of further effects, one of which is to enable memorization (Rubin 1995, Lea et. al 2008). However it seems that memorization is improved if the auditor is unaware of the sound patterning (Lindstromenberg and Boers 2008: 206). Another very interesting psychological characteristic of sound patterning is that the fluency of processing which it involves can be "misattributed to other psychological dimensions" (McGlone and Tofighbakhsh 2000: 427). Thus for example, aphorisms which rhyme are more likely to be held to be true than aphorisms which do not: "rhyme, like repetition, affords statements an enhancement in processing fluency that can be misattributed to heightened conviction about their truthfulness" (McGlone and Tofighbakhsh 2000: 424). Again, this effect is reduced if the hearer's attention is drawn to the sound patterning. The fact that these extra effects of sound patterning work better if the sound patterning is not noticed contrasts interestingly with Jakobson's (1960) view, that sound patterning (and other kinds of formal constraint) bring out the poetic function of language precisely because they are noticed.

I conclude by briefly describing the alliteration pattern in Somali poetry (Banti and Giannattasio 1996: 84), as it relates to the Development Hypothesis. The initial sound of at least one lexical word in each line or half-line is repeated, with the same sound repeated throughout the poem; this by itself is in keeping with the Hypothesis, and even more so, the fact that initial different vowels alliterate with each other (interpreted within the tradition by assuming an initial glottal) which is crosslinguistically attested and specifically discussed by Kiparsky (1970: 170). However, this is a language which has systematic alliteration but does not have systematic initial stress (tonal accent in Somali is not necessarily word-initial), so in this case there is no strong tie between the literary practice and the phonology of the language (not contrary to, but also not supporting, the Development Hypothesis). Furthermore, it is worth noting that the alliteration can be organized sequentially by "alif-ka-ya alliteration where the sound is changed at each stanza following usually the order of the Arabic alphabet." The order of the alphabet is a non-linguistic constraint (i.e., falling outside the Development Hypothesis) but is here implicated in the literary practice, and this raises the question of whether Somali alliteration should be considered as an overt and artificially composed constraint about which the Hypothesis has nothing to say.

\subsection{Lexical-syntactic parallelism}

Lexical-syntactic parallelism is a relation between two sections of text which are formed from similar syntactic constituents (sometimes sequenced differently), and words which are similar (usually synonyms or antonyms). Here is an example, from Rotinese.

Lena-lena ngala lemin

Lesi-lesi ngala lemin

Sadi mafandendelek

Sadi masanenedak
All you great ones, All you superior ones, Do remember this, Do bear this in mind: 
Fo ana-ma tua fude

Ma falu-ina beba langa la
Save the froth of the cooking syrup for the orphans

And the heads of the palm leaf-stalks for the widows.

Fox (1988: 167)

Parallelism is a basic structural principle in much non-metrical verse. It is also a concern of classical rhetoric, where various rhetorical figures define varieties of parallelism, including for example zeugma, where parallel syntactic structures share a word which is stated only in one of the parallel structures. Each of the lines below has an example of zeugma; note how complex the syntax is in these lines (perhaps tending towards 'crazy' syntax, and perhaps organized by concatenation not by syntax, see 2.2).

Who could not win the mistress, wooed the maid.

And now a bubble burst, and now a word.

Where nature moves, and rapture warms the mind.

Alexander Pope (Lanham 1991: 160, citing Wimsatt)

Inspired by the eighteenth century discovery of parallelism in the Bible by Bishop Lowth, Biblical scholars have explored parallelism in ancient Hebrew and other ancient Near Eastern languages. Fox (1988) and others have explored parallelism in Indonesian oral literatures. Poppe (1958) has explored parallelism in Mongolian. Studies of central American literatures have also shown the extensive use of parallelism.

An interesting question about parallelism is whether it is strictly dependent on syntactic constituency as a rule, or whether it can ignore syntactic structure: where two sequences of words are in a parallel structure, do those sequences always constitute well-formed constituents (see Fabb 1997: 148 on ellipsis)? Another question relates to the way in which the paired terms together produce a meaning which cannot be predicted from the terms in isolation (I return to this in section 4). These are important issues for the Development Hypothesis. With parallelism, we face a problem we have seen before, which is that ordinary language and literary language are not always clearly differentiated, and thus the motivation for the Development Hypothesis, which requires a separation between them, is here weakened. In parallelism, there may be a continuum between ordinary speech, various kinds of heightened speech, and literature proper, with increasing amounts of parallelism in each (see for example Gossen 1989, on speech genres of the Tzotzilspeaking Chamula).

\subsection{Non-linguistic constraints}

So far I have discussed various superadded constraints which are clearly related to the cognitive organization of language; these all satisfy the Development Hypothesis. However, there are other constraints on literary language, which either control 
somewhat arbitrary aspects of linguistic form, or control linguistic form only indirectly.

An example of arbitrary control over linguistic form is provided by abecedarian texts, whose parts are sequenced to follow the non-linguistic sequence of the alphabet: each of the twenty-three stanzas of the Hiberno-Latin 'Altus Prosator' begins with a different letter of the Roman alphabet, in sequence (Crawford and Imlah 2000: 2). Pattern poems demonstrate another type of arbitrary control, where each line is a component part of a picture, and this nonlinguistic constraint determines the length of the line (and indirectly other linguistic characteristics). An early example is Theocritus's "Shepherds pipe" where each line-pair is one syllable shorter than the preceding, to produce either an image of the shape of a pipe, or possibly a visualization of the descending sounds produced by the pipe (Edmonds 1912: 500). Fabb and Halle (2008) present a similar argument that some of the Biblical psalms are pattern poems.

An example of indirect control over linguistic form can be seen in a technique chosen by particularly skilled folk singers from Kars and Erzurum (Eastern Turkey). "A unique singing style has been developed there: dudak degmez ("the lips do not touch each other'). The singer puts a pin perpendicularly between his lips, thus preventing them from touching while he sings. ... The technique can only be successful if the letters $v, m, p, f, b$ or $\ddot{o}$ do not occur in the text." (Reinhard 1993: 12). The underlying constraint is physiological, not linguistic, but because it controls the lips it indirectly picks out a linguistically definable set of sounds, those with a labial component. Is this a purely physiological constraint, or is it mediated via linguistic cognition such that all words with a +labial sound are suppressed in composition? The answer has a bearing on the Development Hypothesis.

Non-linguistic constraints on literary language are characteristic also of much avant-garde poetry, and are particularly associated with the writers assigned to the Oulipo movement, whose 'potential literature' includes arbitrarily introduced constraints (Mathews and Brotchie 2005). In avant-garde poetry and other writing, any constraint can be imposed, including many constraints which clearly violate the Development Hypothesis. Of course, it will always be technically possible to impose an arbitrary constraint on a text. Two questions always arise. First, is the constraint as arbitrary as it first seems, or does it potentially involve linguistic cognition (as in the case of dudak değmez)? Second, how repeatable is the experiment of adding such a constraint: does it spread as a practice or become traditional? This second question implies that only constraints which survive across a set of texts, and preferably also a group of poets, should be expected to conform to the Development Hypothesis. The Development Hypothesis thus requires a three-way partitioning of language, into ordinary language, 'traditional literary language' (in the sense of literary language which spreads, or forms a tradition), and 'artificial literary language'; only traditional literary language is subject to the Development Hypothesis.

\section{Interpretation, literary texts, and the Development Hypothesis}

Are literary texts are interpreted in a different way from ordinary texts, and if so, can any differences be understood in terms of 'development'? It seems quite unlikely that literary texts are interpreted in a different way. There are kinds of 'meaning' such as metaphor or irony which are characteristically associated with literary texts, but these can be explained in terms of any ordinary pragmatics. It is possible that literary 
language differs quantitatively from ordinary language, for example in having more metaphor over a shorter amount of text (characteristic of poetry, for example), but this is a literary 'development' of ordinary language only in a loose sense. In the remainder of this short section I consider some specific examples of literary traditions which identify literature-specific ways of using language which are said to have specific interpretive consequences.

The first example comes from Asmat songs (New Guinea), as described by Voorhoeve (1977). In these songs, ordinary words can be assigned new meanings: for example, cem (which ordinarily means 'house') can mean 'carrying bag' when used in a song. The ordinary word for 'carrying bag' is ese, and both cem and ese can be used in the same song with the same meaning. (It is also possible to invent a word: okom is an invented word meaning 'water' which can be used alongside the ordinary word $m u$ 'water'.) Is this different from ordinary language, and if so, is it a development of a possibility found in ordinary language? One possibility is that we are simply looking at neologisms, in both the re-use of an ordinary signifier cem and the invented word okom; hence this is an ordinary language possibility. But it is also worth asking whether cem (ordinarily 'house') is here (meaning 'carrying bag') a kind of metaphor, an alteration of the basic concept. A further intriguing question is whether - as often in metaphors - the basic concept also survives alongside the newly introduced concept, so that cem means 'carrying bag' but also 'house'.

Another interesting phenomenon in the interpretation of literary texts involves a range of practices which we might group together as 'hendiadys'. In classical rhetoric, the device of hendiadys involves a syntactic conjunction which is not interpreted as a conjunction; instead, the two conjoined elements may be interpreted as communicating a single concept: for example Virgil says "we drink from cups and gold" (pateris libamus et auro), which is interpreted as 'from golden cups' (Watson 2001: 4). Hendiadys is found also in ordinary language, as for example in "His dinner was nice and hot" meaning something like 'nicely hot' (Huddleston and Pullum 2002: 1302). Thus it seems that the literary device is a development of an ordinary language device and thus conforms to the Development Hypothesis. Following Blakemore's (2008) proposal about the interpretation of certain kinds of apposition, hendiadys might be thought of as the building of a hybrid representation developed from two distinct concepts, which produces a wider array of implicatures than can be recovered from each of the two original parts. It may be that hendiadys and the construction of hybrid concepts is also a factor in parallelism, and the interpretation of pairs of words. For example, in the parallelistic Rotinese text quoted in section 3.4, the pairing of 'orphans' and 'widows' communicates a single concept 'the bereaved' (Fox 1988: 166), and this appears to be another variant on hendiadys. A similar situation arises in Chinese literature, where parallel terms together express a broader meaning than is semantically determined by the co-ordination of the individual items. Thus in the couplet 'Grieves for the falling leaves in strong autumn, / Rejoices in the pliant branches in sweet spring'... "while the determinations made by the specific propositions are true (he 'grieves' in autumn and does not 'rejoice'), the couplet implicates a full range of emotional response to the cycles of nature." (Owen 1992:91). Thus a theory of hendiadys, which should hold both for ordinary and literary language, might offer further insight into the characteristically literary device of parallelism.

The interpretation of a literary text is characteristically more difficult; the set of derived implicatures may be more obscure, ambiguous, indeterminate, uncertain, 
and paraphrasable. Consider, for example, the following statement, summarizing Lu Chi's Poetic Exposition on Literature (Chinese, c.280 AD): “[M]eaning is an event that occurs beyond words and 'after the words have ended'. Without that sense of some significance, flavor, or whatever beyond the surface of the text, the literary work seems flat. The use of the $p$ 'ien-yen, the 'suggestive expression' or literally 'partial expression,' marks the incompleteness of the surface text; and it is such language, recognized as somehow incomplete, that is the 'riding crop,' giving the text energy and forward momentum." (Owen 1992:149). As another example, consider the practice associated with the Nath religion of Northern India, of composing vernacular poetry in an 'upside down language', an "obscure allusive style in which suggestive dualities and incongruities (ultāba ams $\bar{\imath}$ ) asserted as paradoxical truths bear much of the meaning" (McGregor 1984: 22). Though these are from critical traditions quite distinct from post-Romantic western literary theory, there is a shared idea that literature is particularly difficult to interpret.

This particular difficulty can however be seen as a development of the general possibility of difficulty (indeterminacy, ambiguity, etc) which is true of all language. The key difference may not be the kinds of difficulty but the amount of difficulty, as Sperber and Wilson (1995: 236) suggest: "In general, the wider the range of potential implicatures and the greater the hearer's responsibility for constructing them, the more poetic the effect, the more creative the metaphor." (For further discussion of poetic effects, see also Pilkington 2000.)

\section{The Development Hypothesis}

\subsection{Is the Development Hypothesis correct?}

The Development Hypothesis says that the form of literary language and the rules and constraints which hold of it are developments of the form, rules, and constraints of ordinary language. As we have seen, in some cases it is trivially true; in other cases it seems to be true in the stricter sense that the literary language is a development of its own source language, while in other cases it is true in the weaker sense that a literary language is a development of a general linguistic possibility. As Kiparsky argues, truly arbitrary constraints (such as kinds of sound patterning which have no basis in the organization of language) do not tend to hold: they are found in isolated (avantgarde) texts but they do not generally form traditions.

Even where there are dependencies, there are also gaps between the literary language and the ordinary language. First, though rhyme and alliteration may develop from morphological rules, they hold over greater distances (i.e., not at the lexical level). Second, we probably want to differentiate between ordinary language as generated and literary language as constrained: literary rules rarely make the language exist, but rather place constraints on what the linguistic output can be. Third, literary language is organized into non-linguistic sections, such as lines, which bear very little if any resemblance to linguistic forms. Fourth, counting plays an important role in literary language (in metre, in stanza formation, in parallelism), but counting has function in language as such.

The Development Hypothesis depends on linguistic cognition being subject to different rules and constraints than other kinds of cognition, a foundational idea of generative linguistics (and incidentally, giving the Development Hypothesis its 
primary home in generative literary linguistics). To the extent that literary language avoids having linguistic structure, the Development Hypothesis is weakened. For example, if words are combined by concatenation (a general, not specifically linguistic procedure) rather than by merge (the specifically syntactic rule), the text will have an attenuated linguistic form. I have argued (section 2.2, Fabb 2009a) that this may generally characterize the combination of words and phrases in verse: if so, verse begins to break away from the Development Hypothesis.

More work needs to be done to establish that the Development Hypothesis is correct, and to deal with potential problems (as described in the preceding two paragraphs).

\subsection{What explains the Development Hypothesis?}

Why, when literary language is differentiated from ordinary language, should the differentiation often work by developing ordinary forms and constraints/rules, rather than by introducing some arbitrary form or arbitrary constraint or rule? In other words, why in general does literary language conform to the Development Hypothesis? I suggest that the answer relates to the fact that literary texts are valued, in part because literary language differs from ordinary language, and may be subject to superadded constraints. Composition of such texts is difficult, which makes them rare (and hence valuable), and requires skill and sometimes professional training, which are both valued. These kinds of value do not depend on the language of the text conforming to the Development Hypothesis: avant-garde texts, with arbitrarily imposed constraints, can deliver these kinds of value just as easily as other literary texts. However, there are reasons to think that the Development Hypothesis allows a text to acquire other kinds of value, and this would explain why the Development Hypothesis tends to hold for texts which are part of developing and valued traditions.

One possible answer relates to the side-effects apparently produced by texts which have certain kinds of regular form. Thus, McGlone and Tofighbakhsh (2000: 424) suggest that "rhyme, like repetition, affords statements an enhancement in processing fluency that can be misattributed to heightened conviction about their truthfulness". Here the imposition of an external constraint seems to have as a side effect the impression of conviction or familiarity or other effects which may increase the perceived value of a text. Perhaps the constrained or altered language is processed fluently only if it exploits already-existing linguistic knowledge and procedures. Thus rhyme may have the additional effects mentioned by McGlone and Tofighbakhsh only if it makes linguistic sense, rather than being arbitrarily organized.

Another explanation of the Development Hypothesis depends on the idea that literary language is more complex than ordinary language, and that this complexity is valued, perhaps because it has affective or epistemic cognitive effects. The argument goes like this. The complexity of an object or system might for cognitive purposes be measured not by the number of co-existing elements, but rather by the interactions between those elements. Where arbitrary constraints (i.e., falling outside the Development Hypothesis) are imposed on a text, they do not increase the complexity of the text as an object or system: if a text is subject to the requirement that the letter e is never used (George Perec's novel, La Disparition) then it is difficult to compose but not more complex than an ordinary text. In contrast, where a constraint is a development of the linguistic form of the text or the rules or constraints which hold of the language of the text, that constraint interacts, and so adds to the complexity of the 
text. Support for the idea that constraints which conform to the Development Hypothesis also increase the complexity of the text comes from two general facts about these constraints: they are limited in what they can do, and they are limited in how they can interact. The fact that we can see limitations in these constraints suggests that complexity is precisely calibrated in a literary text: a certain degree of complexity is desirable, but not too much complexity (as Fabb 2009b argues). An example of constraints being limited in what they can do is that metrical rules cannot see syntactic structure. Another example is that metrical rules are usually limited to a partitioning of syllables into two classes, even where the language offers a greater range of division (e.g., Vietnamese has six phonemic tones, but for metrical purposes these are grouped into just two tone classes). An example of constraints being limited in how they can interact is that rules which count syllables can usually share information (i.e., the numerical position of a syllable) with just one other type of rule, usually a prosodic/rhythmic rule. For example, Icelandic dróttkveett poems have rules for syllable counting, stress, rhyme and alliteration, but only the first two rules can interact; the others operate independently of the others. In summary, this argument suggests that arbitrarily imposed constraints do not contribute to the complexity of the text, while constraints which develop linguistic form do contribute, and so are able to deliver a different kind of valued cognitive effect.

\section{$\underline{\text { Acknowledgements }}$}

Thanks to Diane Blakemore, Jonathan Hope, and Elspeth Jajdelska for comments.

\section{References}

Austin, T. R., 1984. Language Crafted. A Linguistic Theory of Poetic Syntax. Indiana University Press, Bloomington.

Banti, G., Giannattasio, F., 1996. Music and metre in Somali poetry. In: Hayward, R. J., Lewis, I.M. (eds.), Voice and Power. The Culture of Language in North-East Africa. School of Oriental and African Studies, London. pp. 83-128.

Blackings, M., Fabb, N., 2003. A Grammar of Ma'di. Mouton, Berlin.

Blakemore, D., 2008. Apposition and affective communication. Language and Literature 17.1., 37-57.

Constable, J., Aoyama, H., 1999. Word length frequency and distribution in English: Part II. An empirical and mathematical examination of the character and consequences of isometric lineation. Literary and Linguistic Computing 14.4, 507535.

Crawford, R., Imlah, M., 2000. The New Penguin Book of Scottish Verse. Penguin, London.

Dixon, R. M.W., Koch, G., 1996. Dyirbal Song Poetry. The Oral Literature of an Australian Rainforest People. University of Queensland Press, St Lucia.

Edmonds, J.M., 1912. The Greek Bucolic Poets. (The Loeb Classical Library) William Heinemann, London.

Fabb, N., 1997. Linguistics and Literature: Language in the Verbal Arts of the World. Blackwell, Oxford. 
Fabb, N., 1999. Verse constituency and the locality of alliteration. Lingua 108, 223245.

Fabb, N., 2002. Language and Literary Structure: The Linguistic Analysis of Form in Verse and Narrative. Cambridge University Press, Cambridge.

Fabb, N., 2009a. Why is verse poetry? PN Review 189.

Fabb. N., 2009b. Formal interactions in poetic metre. In: Dewey, T.K., Frog, (Eds.), Versatility in Versification: Multidisciplinary Approaches to Metrics. Peter Lang.

Fabb, N., Halle, M., 2008. Metre in Poetry: A New Theory. Cambridge University Press, Cambridge.

Fitzgerald, C. M., 2007. An optimality treatment of syntactic inversions in English verse. Language Sciences 29, 203-217.

Fox, J. J. (Ed.) 1988. To Speak in Pairs. Essays on the Ritual Languages of Eastern Indonesia. Cambridge University Press, Cambridge.

Golston, C., Riad, T., 2000. The phonology of Classical Greek metre. Linguistics 38, 99-167.

Gossen, G., 1989. To speak with a heated heart: Chamula canons of style and good performance. In: Bauman, R., Sherzer, J. (Eds.), Explorations in the Ethnography of Speaking. Cambridge University Press, Cambridge. pp. 389-413.

Halle, M., Keyser, S.J., 1971. English Stress: its Form, its Growth, and its Role in Verse. Harper and Row, New York.

Hanson, K., Kiparsky, P., 1996. A parametric theory of poetic metre. Language, 72, 287-335.

Hayes, B., 2008. Faithfulness and componentiality in metrics. In: Hanson, K., Inkelas, S., (Eds.) The Nature of the Word. Studies in Honor of Paul Kiparsky. MIT Press, Cambridge MA. pp. 113-148.

Holtman, A., 1996. A generative theory of rhyme: an optimality approach. $\mathrm{PhD}$ thesis, Utrecht University.

Huddleston, R., Pullum, G.K. 2002. The Cambridge Grammar of the English Language. Cambridge University Press, Cambridge.

Idsardi, W. J., 1992. The Computation of Prosody. Doctoral dissertation MIT, Cambridge MA.

Jakobson, R.,1960. Closing statement: Linguistics and poetics. In: Sebeok, T. (Ed.) Style in Language. MIT Press, Cambridge MA. pp. 350-377.

59-93.

Kiparsky, P., 1970. Metrics and morphophonemics in the Kalevala. In: Freeman, D.C. (Ed.), Linguistics and Literary Style. Holt, Rinehart, Winston, New York. pp. 165181.

Kiparsky, P., 1981. The role of linguistics in a theory of poetry. In: Freeman, D.C. (Ed.) Essays in Modern Stylistics. Methuen, London. pp. 9-23.

Knott, E., 1994. An Introduction to Irish Syllabic Poetry of the Period 1200-1600. 2nd edition. Dublin Institute for Advanced Studies, Dublin.

Lanham, R. 1991. A Handlist of Rhetorical Terms. Second edition. University of California Press, Berkeley.

Lea, R. B., Rapp, D. N., Elfenbein, A, Mitchel, A.D., Romine, R.S., 2008. Sweet Silent Thought. Alliteration and Resonance in Poetry Comprehension. Psychologial Science 19.7, 709-716. 
Lerdahl, F., 1988. Cognitive Constraints on Compositional Systems. In: Sloboda, J.A., (Ed.) Generative Processes in Music. the Psychology of Performance, Improvisation, and Composition. Clarendon Press, Oxford. pp. 231-259.

Lindstromenberg, S., Boers, F. 2008. The Mnemonic Effect of Noticing Alliteration in Lexical Chunks. Applied Linguistics 29.2, 200-222.

MacMahon, B., 1995. The Freudian slip revisited: a case of mistaken identity in Finnegans Wake. Language \& Communication 15.4, 289-328.

Malone, J. L., 1982. Generative phonology and Turkish rhyme. Linguistic Inquiry, $13.3,550-553$.

Mathews, H., and Brotchie, A., 2005. Oulipo Compendium. Revised and Updated. Atlas Press, London.

McGlone, M.S., Tofighbakhsh, J., 2000. Birds of a feather flock conjointly (?): Rhyme as reason in aphorisms. Psychological Science. 11.5.

McGregor, R. S., 1984. Hindi Literature from its Beginnings to the Nineteenth Century. (A History of Indian Literature. Vol VIII, Fasc. 6.) Otto Harrassowitz, Wiesbaden.

ONeil, W., 2001. Grammar games: unscrambling Skaldic syntax. Kenstowicz, M., (ed.) Ken Hale. A Life in Language. MIT Press, Cambridge MA. pp. 339-354

Owen, S., 1992. Readings in Chinese Literary Thought. Harvard University Press, Cambridge MA.

Pilkington, A., 2000. Poetic Effects. A Relevance Theory Perspective. John Benjamins, Amsterdam.

Poppe, N. 1958. Der Parallelismus in der epischen Dichtung der Mongolen. UralAltaische Jahrbücher, 30. 195-228.

Reinhard, U., 1993. Song creators in Eastern Turkey. (Booklet accompanying Smithsonian Folkways CD of the same name.)

Rothenberg, J., Joris, P., 1995. Poems for the Millennium. volume 1. University of California Press, Berkeley.

Rothenberg, J., Joris, P., 1998. Poems for the Millennium. volume 2. University of California Press, Berkeley.

Rubin, D. C., 1995. Memory in Oral Traditions. The Cognitive Psychology of Epic, Ballads, and Counting-out Rhymes. Oxford University Press, Oxford.

Sapir, E., 1967 Language. An Introduction to the Study of Speech. Harcourt, Brace and World, New York.

Sperber, D., Wilson, D., 1995. Relevance: Communication and Cognition. 2nd edition. Blackwell, Oxford.

Stanford, J. N., 2007. Sui adjective reduplication as poetic morpho-phonology. Journal of East Asian Languages 16, 87-111.

Voorhoeve, C. L., 1977. Ta-poman: metaphorical use of words and poetic vocabulary in Asmat songs. Pacific linguistics, volume C,19-38.

Watson, G. T. 2001. Hearing the Measures. Shakespearean and Other Inflections. University of Wisconsin Press, Madison.

Wexler, P. J., 1966. Distich and sentence in Corneille and Racine. in Fowler, R. (Ed.) Essays on Style and Language. Linguistic and Critical Approaches to Literary Style. Routledge and Kegan Paul, London. pp.100-117. 
Worth, D. S., 1977. Roman Jakobson and the study of rhyme. In: v. Schooneveld, C. H., D. Armstrong, D. (Eds.), Roman Jakobson: Echoes of his Scholarship. Peter de Ridder Press, Lisse. pp.515-533.

Yip, M., 1999. Reduplication as alliteration and rhyme. GLOT International. 4, 1-7. 